\title{
Data frauds, health risks, and the growing question of ethics during the COVID-19 pandemic
}

\author{
Quan-Hoang Vuong ${ }^{1,2}$, Tam-Tri Le ${ }^{1,2}$, Minh-Hoang Nguyen ${ }^{1,2}$,* \\ ${ }^{1}$ Centre for Interdisciplinary Social Research, Phenikaa University, Yen Nghia Ward, Ha \\ Dong District, Hanoi 100803, Vietnam \\ ${ }^{2}$ AISDL, Vuong \& Associates, Dong Da District, Hanoi 100000, Vietnam \\ * Correspondence: hoang.nguyenminh@phenikaa-uni.edu.vn
}

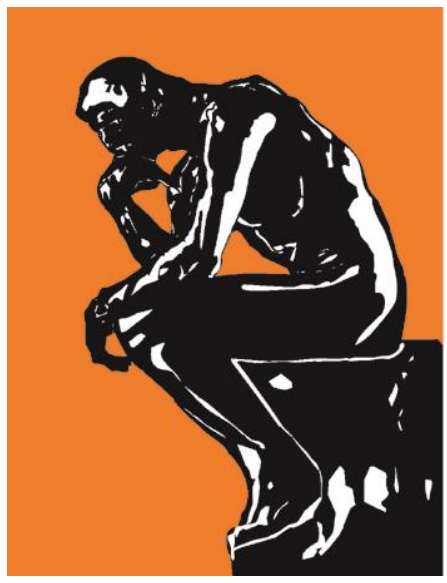

Un-peer-reviewed working draft, version 4

October 28, 2021

In nearly two years under the global health crisis of the Covid-19 pandemic, ethical issues regarding health data have been emerging quickly to the central focus of the global scientific community. Many papers have been retracted because of data problems, including those from top prestigious journals. For example, two papers on The Lancet and New England Journal of Medicine (NEJM) were retracted due to concerns regarding the veracity of datasets (Ledford \& Van Noorden, 2020). Elisabeth Bik, an academic image sleuth, has found that $4 \%$ of more than 20000 biomedical papers she checked contained problematic image duplications; and her efforts have led to at least 172 retractions (Shen, 2020). When the lives and well-being of countless people are at stake, and all eyes are on science, such mistakes could be (and have been) disruptive toward public trust, which might further fuel conspiracy theories and science-denying attitudes (Ball \& Maxmen, 2020). We require health data of good ethical standards, but who will be responsible if such standards are not met? 
At first glance, the authors of the studies should be responsible for academic integrity since they are the ones who conduct the data collection and analysis. Ethical violations can be categorized into two groups: intentional and unintentional fraud. In the cases of intentional fraud, it is obvious that the articles should be retracted, and the authors should be punished for their misconducts, such as removal from professional positions. For example, anesthesiologist Joachim Boldt had fabricated data and committed other ethical violations, which led to nearly 90 retractions upon investigation and himself stripped of the professorship (Brainard \& You, 2018).

However, when the ethical violations are done unintentionally, and retractions only help improve scientific transparency (Vuong, 2020), who else besides the authors need to be held responsible? Firstly, it is the journal - or to be precise, all those involved in the publishing process (editors and reviewers). Academic journals, especially the top prestigious ones, often proudly present their claims for high-quality articles, which, in theory, have all gone through vigorous cross-checking procedures. As stated by the $N E J M$ that "each published $N E J M$ manuscript benefits from hundreds of hours of work by editors, statistical experts, manuscript editors, illustrators, proofreaders, and production personnel, who work to ensure that every paper meets exacting standards" it is clear that a publication is a product of various experts' involvement besides the authors - thus, they should all be held accountable for the publication's errors.

Secondly, the ethical committees with the role of guaranteeing the studies being done ethically as well as funders providing financial and material support also have the responsibility of pre-assessing whether the registered studies' methodology is compliant with ethical codes.

In a recent well-known incident, a controversial paper suggesting the usage of hydroxychloroquine as an effective Covid-19 treatment was published in the International Journal of Antimicrobial Agents. One of its co-authors - Didier Raoult - is that journal's editor-in-chief (Marcus, 2020). Donald Trump (former President of the United States) and Jair Bolsonaro (President of Brazil) endorsed the paper's findings and encouraged the use of hydroxychloroquine. However, the review of Rosendaal (2020), a part of the review commissioned by the International Society of Antimicrobial Chemotherapy (ISAC), indicated that "this study suffers from major methodological shortcomings which make it nearly if not completely uninformative." Indeed, the World Health Organization (WHO) strongly recommends against using hydroxychloroquine for Covid-19 treatment because it has little or no effect and may increase the risk of diarrhea, nausea, abdominal pain, drowsiness, and headache (World Health Organization, 2021). Given the "methodological shortcomings", including data collection and analysis design, it is obscure why this study was supported by the French Government and ethically approved by the French Ethics Committee (CPP Ile de France) in the first place (Gautret et al., 2020). 
Some studies' data are not collected by the authors but provided by external parties (such as data-vending companies). For instance, the Surgical Outcomes Collaborative (Surgisphere Corporation, Chicago, IL, USA) was the external company that supplied data for the two retracted papers on The Lancet and NJEM (Ledford \& Van Noorden, 2020). In both papers, the authors stated, "the data collection and analyses are deemed exempt from ethics review" as a result of using Surgisphere's data (Mehra, Desai, Kuy, Henry, \& Patel, 2020; Mehra, Desai, Ruschitzka, \& Patel, 2020). Nevertheless, when the veracity of the data and analyses were concerned, the authors could not access the raw data and determined to retract the studies. Therefore, it is crucial to raise the question: "should scientists put the research integrity of health data in the hands of commercial companies?"

Normally, after the ethical violations have been acknowledged, the articles are retracted, and the authors are disciplined by affiliated institutions and corresponding organizations. However, what would happen in cases where ethical standards are violated directly by the governments? During the Covid-19 pandemic, many countries, including Israeli, South Korea, and Taiwan, used digital technology to collect personal information for enhancing contact tracing and monitoring without consent (Mello \& Wang, 2020). In Vietnam, the government sticks a label announcing Covid infected cases in front of patients' houses without acquiring their permission. The national television broadcaster of Vietnam also filmed Covid-19 patients while they were on the edge of death without any face-concealing measures and broadcasted the records nationwide without their consent (Điểu, 2021). These activities indeed violate the World Medical Organization's international code of ethics "to respect a patient's right to confidentiality".

Some scholars argue that "sometimes it is unethical not to use available data" (Hand, 2018). Fairly speaking, during the pandemic, the government sometimes needs to quickly arrive at important decisions that require compromises in one way or another. However, how can we justify governments breaching ethical codes or using data without consent when facing imminent threats? When a study is deemed to violate data ethics, external parties such as independent ethics review boards will be in charge of auditing the matter. In the case of the government, who will take on that role?

Evidence-based policymaking is one of the most important implications of health research because it bridges practical impacts and insights derived from studies. The government's attitude toward health data ethics can greatly influence the attitude of scientists in health research disciplines. If scientists perceive that their efforts to uphold academic integrity are meaningless in the face of nation-scale violations (Vuong, 2018), the ethical standards within the scientific community would be undermined. For these reasons, even though we have yet got answers to the questions posed above, we advocate that the issue of health data ethics should no longer be considered on the level of individual scientists or research labs, but rather as a problem involving all stakeholders, from publishers, funders, ethical committees to governments, for the sake of research integrity. 


\section{References}

Ball, P., \& Maxmen, A. (2020). The epic battle against coronavirus misinformation and conspiracy theories. Nature, 581(7809), 371-375.

Brainard, J., \& You, J. (2018). What a massive database of retracted papers reveals about science publishing's 'death penalty'. Science, 25(1), 1-5.

Điểu, T. (2021). Phim 'Ranh giới' không làm mờ mặt: Thiếu nhân bản hay trân trọng mọi hiện hữu của con người? Retrieved from https://tuoitre.vn/phim-ranh-gioi-khonglam-mo-mat-thieu-nhan-ban-hay-tran-trong-moi-hien-huu-cua-con-nguoi2021090912363207.htm

Gautret, P., Lagier, J.-C., Parola, P., Meddeb, L., Mailhe, M., Doudier, B., ... Raoult, D. (2020). Hydroxychloroquine and azithromycin as a treatment of COVID-19: results of an open-label non-randomized clinical trial. International Journal of Antimicrobial Agents, 56(1), 105949.

Hand, D. J. (2018). Aspects of data ethics in a changing world: Where are we now? Big Data, 6(3), 176-190.

Ledford, H., \& Van Noorden, R. (2020). High-profile coronavirus retractions raise concerns about data oversight. Nature, 582(7811), 160-161.

Marcus, A. (2020). Elsevier investigating hydroxychloroquine-COVID-19 paper. Retrieved from https://retractionwatch.com/2020/04/12/elsevier-investigatinghydroxychloroquine-covid-19-paper/

Mehra, M. R., Desai, S. S., Kuy, S., Henry, T. D., \& Patel, A. N. (2020). RETRACTED: Cardiovascular disease, drug therapy, and mortality in Covid-19. New England Journal of Medicine, 382(25), e102.

Mehra, M. R., Desai, S. S., Ruschitzka, F., \& Patel, A. N. (2020). RETRACTED: Hydroxychloroquine or chloroquine with or without a macrolide for treatment of COVID-19: a multinational registry analysis. The Lancet, 395(10240), P1820.

Mello, M. M., \& Wang, C. J. (2020). Ethics and governance for digital disease surveillance. Science, 368(6494), 951-954.

Rosendaal, F. R. (2020). Review of: "Hydroxychloroquine and azithromycin as a treatment of COVID-19: results of an open-label non-randomized clinical trial Gautret et al. 2010, DOI:10.1016/j.ijantimicag.2020.105949". International Journal of Antimicrobial Agents, 56(1), 106063.

Shen, H. (2020). Meet this super-spotter of duplicated images in science papers. Nature, 581, 132-136.

Vuong, Q.-H. (2018). The (ir)rational consideration of the cost of science in transition economies. Nature Human Behaviour, 2, 5.

Vuong, Q.-H. (2020). Reform retractions to make them more transparent. Nature, 582, 149.

World Health Organization. (2021). WHO Living guideline: Drugs to prevent COVID-19. Retrieved from: https://www.who.int/publications/i/item/WHO-2019-nCoVprophylaxes-2021-1 
